\title{
Correction to "Identification of Abundant and Evolutionarily Conserved Opioid Receptor Circular RNAs in the Nervous System Modulated by Morphine"
}

In the above article [Irie T, Shum R, Deni I, Hunkele A, Le Rouzie V, Xu J, Wilson R, Fischer GW, Pasternak GW, and Pan Y-X (2019) Mol Pharmacol 96: 247-258 DOI https://doi.org/10.1124/mol.118.113977], the following financial disclosure information was accidentally omitted from the footnotes:

YX Pan is a co-scientific founder of Sparian Biosciences. GW Pasternak was a founder of Sparian Biosciences. He was also a consultant and/or speaker of Endo Pharmaceuticals, Confo Therpeutics, Nektar Therpeutics, Collegium Pharmaceuticals, and Novartis.

The authors regret this omission and any inconvenience it may have caused. 